\title{
Transforming Education with Emerging Technologies in Higher Education: A Systematic Literature Review
}

\author{
Ha Duc Ngoc ${ }^{1}$, Le Huy Hoang ${ }^{2} \&$ Vu Xuan Hung ${ }^{1}$ \\ ${ }^{1}$ Department of Formal Vocational Training, Ministry of Labour - Invalids and Social Affairs, Vietnam \\ ${ }^{2}$ Faculty of Technology Education, Hanoi National University of Education, Vietnam \\ Correspondence: Le Huy Hoang, Faculty of Technology Education, Hanoi National University of Education, Hanoi \\ City, Vietnam.
}

Received: July 3, 2020

Accepted: July 29, 2020

Online Published: August 3, 2020

doi:10.5430/ijhe.v9n5p252

URL: https://doi.org/10.5430/ijhe.v9n5p252

\begin{abstract}
This study attempts to understand what is known about key theme findings in transforming education with emerging technologies in higher education by examining existing literature. Based on 5 selection criteria, 24 quality articles were included in the review. Thematic analysis methods are used to analyze and identify key themes in the data. The findings indicate that teachers who have used emerging technologies in teaching, they point out the key factors for transforming education with emerging technologies, including teachers' interest, institutional perspective, teachers' perceptions of the benefits of emerging technologies. They also report a dichotomy between the technologies used for teaching in higher education institutions and the technologies owned and used by students in social life as a major challenge. Teachers believe that the open communication and teamwork environment can be enhanced by using emerging technologies. Pedagogical innovation, empowering educators are essential requirements for teaching with emerging technologies. The 7 findings from this study should be used to guide initiatives for teacher career development to improve the effectiveness of education with emerging technologies.
\end{abstract}

Keywords: emerging technologies; education with emerging technologies; pedagogy with emerging technologies; higher education; teachers' perception

\section{Introduction}

In the 21st century, we are witnessing the transformation of society into a new form, called the information and knowledge society. The technology gradually becomes the main vehicle in the development of a new society. Along with the promotion of industrial development towards automation, technology also has a main purpose of creating an environment of creativity and innovation to unleash the full potential of people. Collective creativity becomes the main driving force for the development of society, instead of focusing on a few elite people. Technology becomes an integral part of the knowledge society, and influences people's behavior. To establish a successful knowledge society, the education system needs to promote the use of technology in the transfer of knowledge, along with new teaching methods. Technology becomes a good tool for improving the education system. Among many technologies, web 2.0 has the most potential to create a big data warehouse and technology-rich learning environments to help people easily access knowledge and skills. They also provide the ability to connect people and form learning communities to increase the value of knowledge.

The rapid growth in demand for internet-based learning is inevitable in a knowledge society. Today, it is not difficult for us to realize that learners are not merely learning in school, their learning is certainly supported by technologies outside the school environment. But schools are really supporting this learning by students or whether schools themselves are hindering students' learning with technology. While the difference between formal and informal learning is determined by whether or not an instructor is, it can be argued that there can be no separation between formal and informal learning (Johnson, Chapman \& Dyer, 2006). This is especially relevant to emerging technologies, where creation tools create opportunities to bridge the gap between teachers and learners in any space or time.

While social media and Web 2.0 technologies continue to change students' learning trends and interests, educators need to grasp the applicability of these new tools in all types of learning environments (Pacansky-Brock, 2013). 
Rapid technological innovation has created an urgent need for educational research that can help us better understand how student learning is being mediated by emerging technologies (Oliveira, Feyzi Behnagh, Mohsinah, Burgess \& Guo, 2019). Teaching practice exists a widening gap between the technologies used by students, the technologies used by educators and those provided by higher education institutions (Gachago, Bozalek \& Ng'ambi, 2013). Although many emerging technologies are commonly used by students, but their pedagogical value is not yet realized. Many teachers are sometimes reminded by their students about using emerging technologies (such as Facebook) that students use in their social lives, to provide informal and formal learning experiences (Gachago et al., 2013).

By examining many of the existing studies, we have provided a complete report on key theme findings in transforming education with emerging technologies in higher education.

\section{Research Questions}

The purpose of the study was to examine existing literature on teachers' perceptions, pedagogical values, and motivating factors in transforming education with emerging technologies. To examine what exists in studies, the following questions were used:

(1) How do existing studies characterize teachers' perception in transforming education with emerging technologies?

(2) The existing studies indicate what values are created in pedagogy with emerging technologies?

(3) The existing studies indicate what changes are needed to promote the transforming education with emerging technologies?

\section{Methods}

\subsection{Data Sources}

This systematic literature review used a guiding procedure proposed by Brocke et al (2009). The ERIC database was primarily used to accurately search for educational-related resources, including articles, books, conference papers, and other education-related materials. For a more thorough search, the Google Scholar database was also used to search for additional studies. Haddaway, Collins, Coughlin and Kirk (2015) suggested that researchers checkup to the first 300 results from Google Scholar to avoid missing out on any literature. The last searches were made on May 30, 2020.

\subsection{Search Strategy}

In systematic literature research, a well-defined literature search strategy is important to enhance the rigor of theoretical data, because incomplete searches can lead to the possibility of inaccurate results (Whittemore \& Knafl, 2005). The code 'AND' was used to combine keyword groups "emerging technologies" or "emerging technology" with keyword groups "teaching" or "leaning" or "education" or "pedagogy". The scope of searches in the ERIC database was limited to peer review studies and published in an academic journal. Studies should also be published in English. They are also needed to address at least one of the research questions.

\subsection{Study Selection}

Figure 1 below shows the literature screening process. To select the appropriate studies, the following criteria were used for the review of abstracts and full text of the articles:

Criteria 1: Study published in English.

Criteria 2: Study published in a peer-reviewed academic journal.

Criteria 3: Participants included students, lecturers of higher education institutions.

Criteria 4: Research is an empirical / survey.

Criteria 5: The research method is clearly described, sufficient evidence, complete results.

A total of 24 articles were selected for review after the screening. 

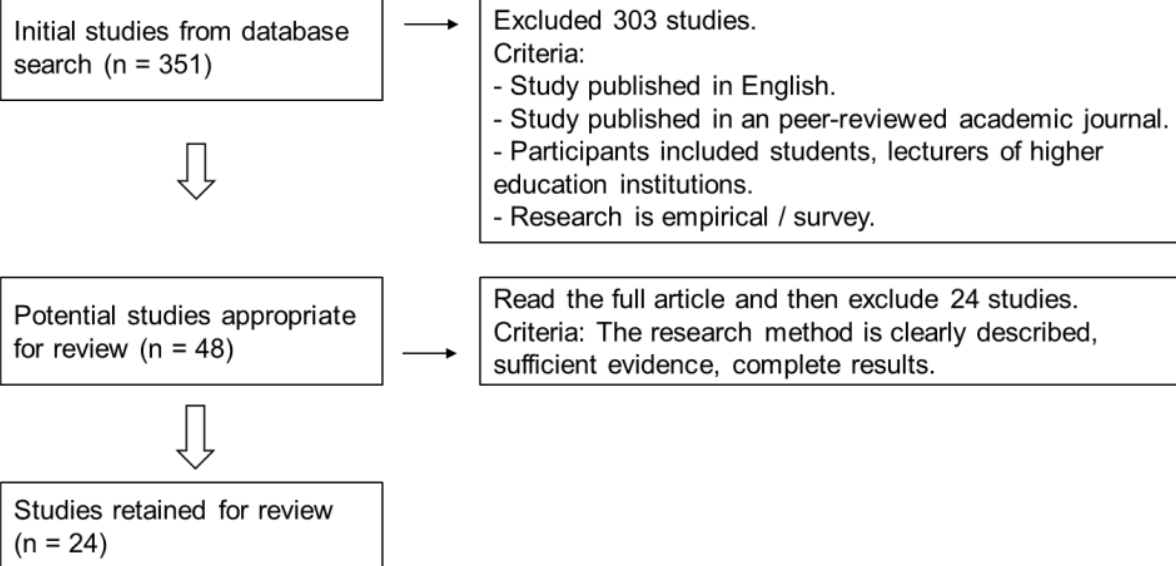

Read the full article and then exclude 24 studies. Criteria: The research method is clearly described, sufficient evidence, complete results.

Figure 1. Diagram of the screening process.

\subsection{Data Analysis}

The thematic analysis method developed by Braun and Clarke (2006) was used to analyze and identify themes in the data. The important information and findings of the qualitative data is analyzed into each meaningful theme. The first phase, we read all the data to record the original ideas and new findings. In the second phase was to perform in the coding interesting features and grouping the data related to each code. The third phase was to put together the code into potential themes, gathering all relevant data for each potential theme. The fourth phase was to examine the working topic about the coding extract, and to form a "map" of analytical thematic. The fifth phase was to refine the specific details of each theme, the overall story of the analysis, and to create clear definitions and names for each theme. Finally, the sixth phase was to select vivid extract examples related to the analysis for research questions, and to produce an academic report of analysis.

We read all 24 articles retained, then discussed to achieve four pre-established coding protocols, including: (1) teachers' perception, (2) educational challenges, (3) educational benefits / values, (4) pedagogical transformation. One author first used these four protocols to code each piece of text extracted from all the articles retained. Five articles were randomly selected for other researchers to code the extracted text segments to extracted text segments to test the reliability among researchers. This resulted in a consensus rate of 0.65 (greater than 0.41 ) indicating that interrater reliability is acceptable (McHugh, 2012). Then, we worked together to refine broad codes into subcodes that can explain directions to theme findings. Finally, about 90 text segments were extracted from the 24 articles retained.

\section{Results}

4.1 How do Existing Studies Characterize Teachers' Perception in Transforming Education with Emerging Technologies?

Finding 1: Teachers' interest and institutional opinion leaders play an important role in transforming education with emerging technologies. The rapid development of technology has both created challenges for educational institutions, but also created excitement among some teachers who are excited to be part of the transition from traditional to modern academics (Yasir Chaudhry \& Malik, 2014). In a study by Backhouse (2013) shows that faculty participating in new technologies are asserting their own creativity and asserting a more positive position in the challenging context of modern higher education. While social media and Web 2.0 technologies continue to change students' learning trends and interests, higher education institutions need to capture the applicability of these new tools in all types of learning environments (Pacansky-Brock, 2013). In a study by Gachago (2013) shows that emerging technologies have a significant influence in enhancing pedagogical practice, particularly regarding timely feedback, cooperation and interaction between educators and students, such as social networking sites, blogs. However, institutional constraints of schools have been shown to affect educators' willingness to use emerging technologies in practice (Gachago, 2013). Therefore, in order to capture the potential of emerging technologies to improve teaching and learning activities, higher education institutions need to create a favorable educational environment by recognizing the influence of emerging technology and developing policies that encourage the participation of all organizational systems with emerging technologies (Gachago, 2013).

Finding 2: The rapid and diverse development of emerging technologies, along with the dichotomy between the technologies used for teaching in higher education institutions and the technologies owned and used by students, 
they create challenges for the transformation of education with emerging technologies. For example, students are increasing the use of emerging technologies, such as text messaging, wikis, social networks and other Web 2.0 applications, but this is not the case with many university lecturers (Ajjan \& Hartshorne, 2008). Ng'ambi (2013) emphasized that the gap between technologies that are supported and used for teaching (such as LMS systems) and used by students, they put pressure on educators as a "chasing game" that makes using pedagogy with emerging technologies ineffective. A survey report of 22 higher education institutions in South Africa with 262 educators who identified themselves as the first to use emerging technologies in teaching, Ng'ambi, Gachago, Ivala, Bozalek and Watters (2012) conclude that educators use a variety of emerging technologies in their teaching practices. This creates a challenge for new teachers to choose which tool is appropriate for their teaching practice.

Finding 3: Teachers who identify themselves as teaching with emerging technologies, they believe that the benefits of emerging technologies (especially Web 2.0) provide many opportunities to encourage collaboration and interaction in both synchronized and asynchronous educational environments. For example, some teachers feel that Web 2.0 technologies can improve students' learning performance, their interaction with teachers and other peers, and their satisfaction with the course; and some teachers choose to use them in their classrooms (Ajjan \& Hartshorne, 2008). In a study by Ajjan and Hartshorne (2008) also shows that teachers' attitudes are strong indicators of their intention to use Web 2.0. In 2012, about 3000 web technologies were reported available online for teachers to use in teaching, and a survey report from 113 lecturers of higher education institutions in Malaysia showed that blogs, social networking sites and video sharing sites are the most commonly used web 2.0 applications by the teachers (Dzulkefli, Sin \& Mohamad, 2012). In a study by Beldarrain (2006) also shows the benefits of using emerging technologies, such as wikis, blogs, and podcasts, to promote multi-dimensional interaction among students.

\subsection{The Existing Studies Indicate What Values are Created in Pedagogy with Emerging Technologies?}

Finding 4: Teachers believe that a teamwork environment can be enhanced by using emerging technologies. For example, Griffith and Liyanage (2008) tested the potential of social networking sites (specifically Facebook) and confirmed that students are very active in using social networks to share in their academic research with group / teamwork (Griffith \& Liyanage, 2008). Because of its high popularity, social networking sites should be used to form research groups, promote research-based projects and even help support learning for distance and on-campus education (Griffith \& Liyanage, 2008). Creating a practice community on Facebook (and other social networks) allows teachers to extend the traditional course time beyond the synchronized meeting, allowing students to participate in asynchronous learning at times that are not only convenient to them, but also able to engage more often with self-expressing ideas or topics (Churcher,2014).

Finding 5: Teachers believe that an open communication environment for knowledge sharing can be enhanced by using emerging technologies. Social media and web 2.0 technologies are an attractive addition to students' learning experiences, especially promoting knowledge sharing inside and outside the classroom (Churcher, 2014). For example, a study by Frydenberg (2006) describes a course where students (rather than teachers) use software tools to create multimedia presentations that reflect their understanding of course topics, and then post them on podcasts. A survey at the end of course shows that the use of podcasts has a positive contribution to the learning of students in the course. An analysis of web server logs also shows that the majority of students download podcast lectures to their mobile devices or laptops (Frydenberg, 2006). Similarly, Peters (2008) proposed using "Chat" as a new pedagogy in higher education to provide a meeting for learners' community to communicate in real-time. In a study by Kang, Bonk and Kim (2011) used blogs as a pedagogical tool for communication platforms in two graduate classes in Korea and showed that discussions in a blog are multi-dimensional and multi-layered interactions between groups; instructors and students can experience decentralized relationships; blogging provides an opportunity to form a social constructivist learning environment (Kang et al., 2011). In another idea, Rambe and Bere (2013) propose using instant messaging on mobile phones as a pedagogical method to promote student engagement. Their findings show the high level of participation of students in order to contribute positively to learning communities for knowledge creation.

4.3 The Existing Studies Indicate What Changes are Needed to Promote the Transforming Education with Emerging Technologies?

Finding 6: Repositioning and innovating pedagogical approaches is an essential requirement for teaching with emerging technologies. The required pedagogical changes are not only related to appropriate teaching methods, but also awareness of learners' experiences and the importance of assessing available learners' skills and making use of them, while exploring and integrating social media to pave the way for students' engagement, social interaction and global networking (McLoughlin \& Lee, 2010). For example, in many situations, teachers sometimes feel unwelcome 
in learners' social networks and online communities (McLoughlin \& Lee, 2010). This presents challenges for teachers to teach in web 2.0 environments using social networks. Rethinking and repositioning of pedagogical approaches in the new educational context of the 21 st century should call for active participation of students in defining their learning goals, and in choosing web 2.0 tools and learning strategies (McLoughlin \& Lee, 2010). In addition, pedagogical innovation requires recognition that user-generated content has a central place in the curriculum to promote self-regulation learning. Kop, Fournier and Mak (2011) emphasize a networked pedagogy for teachers in building connections, collaborating and exchanging resources among people, building a community of learners and harnessing information online.

Finding 7: Empowering educators, fostering learning theories with emerging technologies are necessary requirements to transform teaching with emerging technologies. For example, a survey report with 43 teachers participating in an "emerging technology for improving teaching and learning" course by Cape Higher Education Consortium, South Africa aims to empower educators with pedagogical knowledge for teaching with emerging technologies. The findings show that participants are more interested in learning practices than technology tools. They accept the transition from institutional technologies (such as LMS) to emerging cloud-based technologies that enable immediate informal communication and support and facilitate the building of learning communities (Bozalek, Ng'ambi \& Gachago, 2013). In a study by Lin, Yu, Wang and Ho (2015) argue that understanding the relationship between learning theory and technology is important, because educational practices are rationalized based on proven learning principles and processes. Survey results from 313 teachers from southern Taiwan indicating many teachers believe the use of learning theories plays a fundamental role in the selection of emerging technologies in teaching (Lin et al., 2015). However, a large number of teachers feel that they do not have sufficient knowledge of learning theories in choosing technology for their teaching (Lin et al., 2015). In general, this poses a problem for trainers in developing appropriate professional materials and addressing teachers' needs in a way that connects pedagogical knowledge with emerging technologies.

\section{Conclusions and Recommendations for Future Research}

Many existing studies have demonstrated the positive benefits of using and combining emerging technologies in improving and transforming different educational processes (Sosa, Salinas \& De Benito, 2019). Sustaining technologies may still be valuable, but they will not be able to bring about dramatic changes in education (Norris \& Soloway, 2006). While disruptive technologies (such as web 2.0 and mobile devices) have the potential to drastically impact teaching and learning, and empower learners in ways we can't even imagine (Norris \& Soloway, 2006). Although emerging technologies have the potential to change pedagogical practices (as well as social practices), their potential is largely unfulfilled (Veletsianos, 2010), and also characterized by uncertainty in the given context (Sosa et al., 2019). Therefore, more work needs to be done to understand how best to support teachers as they try to integrate emerging technologies in their classrooms. The 7 findings from this study, which were found through many existing studies, they should be used to guide initiatives for teacher career development to improve the effect of pedagogy with emerging technologies. Because most pedagogical initiatives with emerging technology are in the form of potential, therefore, manuals for new teachers are not available. Most of them are in the pedagogical initiatives of each teacher in using emerging technologies. Therefore, the leaders of higher education institutions should create an open communication environment and teamwork to promote their willingness to share knowledge (Long \& Hanh, 2020).

\section{References}

Ajjan, H., \& Hartshorne, R. (2008). Investigating faculty decisions to adopt Web 2.0 technologies: Theory and empirical tests. The internet and higher education, 11(2), 71-80. https://doi.org/10.1016/j.iheduc.2008.05.002

Backhouse, J. (2013). What makes lecturers in higher education use emerging technologies in their teaching? Knowledge Management \& E-Learning: An International Journal, 5(3), 345-358. https://doi.org/10.34105/j.kmel.2013.05.025

Beldarrain, Y. (2006). Distance education trends: Integrating new technologies to foster student interaction and collaboration. Distance education, 27(2), 139-153. https://doi.org/10.1080/01587910600789498

Bozalek, V., Ng'ambi, D., \& Gachago, D. (2013). Converging institutional expertise to model teaching and learning with emerging technologies. Progressio, 35(2): 19-36. http://hdl.handle.net/10566/3205

Braun, V., \& Clarke, V. (2006). Using thematic analysis in psychology. Qualitative Research in Psychology, 3, 77-101. https://doi.org/10.1191/1478088706qp063oa

Brocke, J. V., Simons, A., Niehaves, B., Niehaves, B., Reimer, K., Plattfaut, R., \& Cleven, A. (2009). Reconstructing 
the giant: On the importance of rigour in documenting the literature search process. ECIS 2009 Proceedings. 161. http://aisel.aisnet.org/ecis2009/161

Churcher, K. (2014). "Friending" Vygotsky: A Social Constructivist Pedagogy of Knowledge Building through Classroom Social Media Use. Journal of Effective Teaching, 14(1), 33-50.

Dzulkefli, Z. M. S., Sin, N. M., \& Mohamad, N. (2012, December). Selection of web 2.0 technologies and teaching practices among lecturers in selected malaysia higher education institutions. In 2012 IEEE Colloquium on Humanities, Science and Engineering (CHUSER), 560-565, IEEE. https://doi.org/10.1109/CHUSER.2012.6504376

Frydenberg, M. (2006, November). Principles and pedagogy: The two P's of podcasting in the information technology classroom. In Proceedings of ISECON, 23.

Gachago, D., Bozalek, V., \& Ng'ambi, D. (2013). Transforming teaching with emerging technologies: Implications for higher education institutions. South African Journal of Higher Education, 27(2), 419-436.

Griffith, S, \& Liyanage, L. (2008). An introduction to the potential of social networking sites in education. In I. Olney, G. Lefoe, J. Mantei, \& J. Herrington (Eds.), Proceedings of the Second Emerging Technologies Conference 2008, 76-81. Wollongong: University of Wollongong. https://ro.uow.edu.au/etc08/9/

Haddaway, N. R., Collins, A. M., Coughlin, D., \& Kirk, S. (2015). The role of google scholar in evidence reviews and its applicability to grey literature searching. PLoS One, 10(9). https://doi.org/10.1371/journal.pone.0138237

Johnson, J., Chapman, C., \& Dyer, J. (2006). Pedagogy and innovation in education with digital technologies. Current Developments in Technology-Assisted Education, 135-139.

Kang, I., Bonk, C. J., \& Kim, M. C. (2011). A case study of blog-based learning in Korea: Technology becomes pedagogy. The Internet and Higher Education, 14(4), 227-235. https://doi.org/10.1016/j.iheduc.2011.05.002

Kop, R., Fournier, H., \& Mak, J. S. F. (2011). A pedagogy of abundance or a pedagogy to support human beings? Participant support on massive open online courses. The International Review of Research in Open and Distributed Learning, 12(7), 74-93. https://doi.org/10.19173/irrodl.v12i7.1041

Lin, C. C., Yu, W. W., Wang, J., \& Ho, M. H. (2015). Faculty's perceived integration of emerging technologies and pedagogical knowledge in the instructional setting. Procedia-Social and Behavioral Sciences, 176, 854-860. https://doi.org/10.1016/j.sbspro.2015.01.550

Long, N.T., Hanh, N.V. (2020). A Structural Equation Model of Blended Learning Culture in the Classroom. International Journal of Higher Education, 9(4), 99-115. https://doi.org/10.5430/ijhe.v9n4p99

McHugh, M. L. (2012). Interrater reliability: the kappa statistic. Biochemia medica: Biochemia medica, 22(3), 276-282. https://doi.org/10.11613/BM.2012.031

McLoughlin, C., \& Lee, M. J. (2010). Personalised and self regulated learning in the Web 2.0 era: International exemplars of innovative pedagogy using social software. Australasian Journal of Educational Technology, 26(1). https://doi.org/10.14742/ajet.1100

Ng'ambi, D., Gachago, D., Ivala, E., Bozalek, V., \& Watters, K. (2012, June). Emerging Technologies in South African Higher Education Institutions: towards a teaching and learning practice framework. In International Conference on e-Learning, 354-362. Academic Conferences International Limited.

Ng'ambi, D. (2013). Effective and ineffective uses of emerging technologies: Towards a transformative pedagogical model. British Journal of Educational Technology, 44(4), 652-661. https://doi.org/10.1111/bjet.12053

Norris, C., \& Soloway, E. (2006, March). Emerging, disruptive technologies for teaching and learning: A brief survey. In Society for Information Technology \& Teacher Education International Conference, 2353-2355. Association for the Advancement of Computing in Education (AACE).

Oliveira, A., Feyzi Behnagh, R., Ni, L., Mohsinah, A. A., Burgess, K. J., \& Guo, L. (2019). Emerging technologies as pedagogical tools for teaching and learning science: A literature review. Human Behavior and Emerging Technologies, 1(2), 149-160. https://doi.org/10.1002/hbe2.141

Pacansky-Brock, M. (2013). Best practices for teaching with emerging technologies. Routledge. https://doi.org/10.4324/9780203095966

Peters, G. B. (2008). Chat as new pedagogy: The emerging communities of learners in higher education. In Encyclopedia of Information Technology Curriculum Integration, 93-98. IGI Global. 
http://doi.org/10.4018/978-1-59904-881-9.ch015

Rambe, P., \& Bere, A. (2013). Using mobile instant messaging to leverage learner participation and transform pedagogy at a South African University of Technology. British Journal of Educational Technology, 44(4), 544-561. https://doi.org/10.1111/bjet.12057

Sosa, E., Salinas, J., \& De Benito, B. (2019). Emerging technologies (ETs) in education: A systematic review of the literature published between 2006 and 2016. International Journal of Emerging Technologies in Learning, 2017, 12(5), 128-149. https://doi.org/10.3991/ijet.v12i05.6939

Veletsianos, G. (Ed.). (2010). Emerging technologies in distance education. Athabasca University Press.

Whittemore R. \& Knafl K. (2005) The integrative review: updated methodology. Journal of Advanced Nursing 52(5), 546-553. https://doi.org/10.1111/j.1365-2648.2005.03621.x

Yasir Chaudhry, M., \& Malik, A. (2014). Intersection of Pedagogy and Emerging Technologies to Enhance Student-Centred Learning in Higher Education. Pakistan Journal of Social Sciences (PJSS), 34(2). 